\title{
TANNIN RESORCINOL FORMALDEHYDE AS POTENTIAL GLUE FOR THE MANUFACTURE OF PLYBAMBOO
}

\author{
Adi Santoso', Yusuf Sudo Hadi², Jamaludin Malik ${ }^{3}$
}

\begin{abstract}
The tannin extracted from mangium (Acacia mangium Wild) tree bark exhibits strong affinity toward formaldehyde when both being reacted forming the tannin formaldehyde polymer which further could serve as resin adhesive. To improve the bonding strength and enhance the curing process, the tannin and formaldehyde is co-polymerized with resorcinol to form tannin resorcinol formaldehyde (TRF) resin. This resin is expectedly useful in the gluing work for the manufacture of reconstituted wood or other ligno-cellulosic products such as plywood, glue laminated timber, and laminated veneer lumber.

In relevant, the tannin extract $(\mathrm{T})$ was prepared from mangium bark, then allowed to copolymerize through the reaction with resorcinol $(\mathrm{R})$ and formaldehyde $(\mathrm{F})$ to produce the TRF resin. In such copolymerization, the mole ratios of $\mathrm{T}: \mathrm{R}: \mathrm{F}$ was such that the mole portion of $\mathrm{R}$ varied at consecutively: $0.2,0.5,0.7,0.9$ and 1.1 , while the mole portion of $\mathrm{T}$ and $\mathrm{F}$ was constant at the ratio of 1 : 1. The course and phenomena that might occur during the TRF polymerization was scrutinized using XRay diffraction (XRD) and Differential Thermal Analysis (DTA) to determine the optimum ratio of T: $\mathrm{R}: \mathrm{F}$ in formulating the TRF adhesive. The resulting formulated TRF was later to be used in the gluing of ply-bamboo assembly consisting of 7 plies, which were virtually the veneers prepared from tali bamboo (Gigantochloa apus) species. The already shaped seven-ply-bamboo further sustained the hotpressing at $20 \mathrm{~kg} / \mathrm{cm}^{2}$ employing $130^{\circ} \mathrm{C}$ for 20 minutes. Afterwards, the resulting 7-ply-bamboo panel was examined of its physical and mechanical (strength) properties, glue-bond quality and formaldehyde emission.

Result revealed that the TRF resin with mole ratio of $\mathrm{T}: \mathrm{R}: \mathrm{F}$ at $1: 0.5: 1$ exhibited the highest crystallinity $(51.33 \%)$ and melting glass transition at $277.14^{\circ} \mathrm{C}$. In addition, the TRF adhesive at such mole ratio exhibited the thermogram and diffractogram characterization which were similar to those of the conventional PRF (phenol-resorcinol-formaldehyde) adhesive. Consequently, the TRF with such ratio was judged as the optimum formulation to be used as adhesive for the gluing of ply-bamboo assembly. The resulting ply-bamboo exhibited particular characteristics, i.e density $0.904 \mathrm{~g} / \mathrm{cm}^{3}, \mathrm{MOR}$ $1,214.62 \mathrm{~kg} / \mathrm{cm}^{2}$, MOE $19,493 \mathrm{~kg} / \mathrm{cm}^{2}$, bonding strength $38,40 \mathrm{~kg} / \mathrm{cm}^{2}$ and zero percent $(0 \%)$ delamination, and formaldehyde emission $0.043 \mathrm{mg} / \mathrm{L}$. The properties of ply bamboo could mostly satisfy, except the MOE, the criteria of Indonesian and Japanese standard for structural that used the conventional non-renewable adhesive (PF and UF). As a result, the TRF adhesive as derived from the renewable stuff (tannin from mangium bark), with remarkably low formaldehyde emission seems more consecutively prospective environmentally friendly, significantly potential to replace sooner or later the non-renewable and less environmentally friendly conventional adhesive (UF and PF), thereby indicatively taking part in greening the environment and mitigating the global warming.
\end{abstract}

Keywords: mangium bark, tannin extract, ply-bamboo, TRF-adhesive

\footnotetext{
${ }^{1}$ Research and Development Center for Forestry Enginering and Forest Products, Jl. Gunung Batu 5 Bogor 16000, Indonesia

${ }^{2}$ Bogor Agricultural University, Forest Products Department, Dramaga Campus Bogor 16680, Indonesia

${ }^{3}$ Research and Development Center for Forestry Enginering and Forest Products, Jl. Gunung Batu 5 Bogor 16000, Indonesia
} 


\section{INTRODUCTION}

Urea formaldehyde (UF) resin exemplifies the adhesive commonly used in Indonesia for the manufacture of wood composite. The main drawbacks of UF are vulnerable to humid weather and water, and give off an enormous amount of formaldehyde emission (Pizzi, 1993).

Tannin-resorcinol-formaldehyde (TRF) as a copolymer presents a relatively new adhesive used in the wood composite industry, distinctively credited with high resistance to boiling water and exerts high bonding strength. The tannin basedadhesives for the gluing of wood-related stuff was prepared by mixing together tannin, resorcinol, and formaldehyde in various mole ratios. Bonding mechanism of the tannin-based adhesive was developed due to the existence of hydrogen bonding and ether linkage bridges (Gardner and Anido, 2002). On the other hand, the wood stuff itself as adherent besides affording hydroxyl groups contains various functional groups, thereby enabling it to perform hydrogen bond with tannin (as polyphenol) and resorcinol (as phenol derivative).

In relevant, this research aimed to look into the most favorable TRF formulation for its application as a glue in the manufacture of plybamboo made from tali bamboo (Gigantochloa

apus). Identification on the phenomena that occurred during the TRF copolymerization was scrutinized using X-Ray diffraction (XRD) and Differential Thermal Analysis (DTA). In this way, the optimum composition of mole fraction of tannin, resorcinol and formaldehyde could be then determined for TRF formulation, further employed in the manufacture of ply-bamboo. Expectedly, this formulated TRF adhesive can exert a remarkable option for its implementation in the wood-based composite industries as well as glue manufacturers, which should sound environmental friendly, including in Indonesia.

Results of the research can expectedly be beneficial to develop a new type of compositeboard or panel products. These new products could satisfy the standard criteria in physical, mechanical and other related properties of the conventional plywood, and concurrently its corresponding formaldehyde emission could conform to the particular stipulation (i.e
Indonesian and Japanese standards). All the related details are forth coming.

\section{MATERIALS AND METHOD}

\section{A. Preparation of Tannin Resorcinol Formaldehyde Adhesives}

Tannin was obtained by extracting it from Acacia mangium bark in hot water with the proportion of 1: $3(\mathrm{w} / \mathrm{v})$. The extract was then filtered by fabric, and the filtrate (passing through the filter) regarded as tannin. The extraction and filtering works were repeated three times. All the tannin extracts were mixed together and then placed in a particular container. Afterward its $\mathrm{pH}$ was adjusted to 10.5 using solution of $40 \%$ $\mathrm{NaOH}$.

The tannin resorcinol formaldehyde (TRF) adhesive was prepared by copolymerizing the extracts (tannin) with resorcinol and formaldehyde. In mole ratios, the portion of resorcinol was vary i.e. 0.2, 0.5, 0.7, 0.9 and 1.1, while the mole ratio between tannin and formaldehyde was equal i.e. $1: 1$.

The course and phenomena that occurred during copolymerization of TRF were observed and scrutinized using the sophisticated DTA and XRD instruments. Such observation and scrutiny were intended to determine the optimum TRF formula of each component (tannin, resorcinol, and formaldehyde). TRF copolymer were then used as the glue for ply-bamboo assembly. Afterwards, the physical and chemical properties, i.e. acidity $(\mathrm{pH})$, solid contents, specific gravity, and viscosity of TRF copolymer adhesive were examined.

\section{B. Ply bamboo Manufacture}

The material for ply-bamboo assembly was from tali bamboo (Gigantochloa apus) species. The size of assembled ply-bamboo measured $40 \mathrm{~cm}$ (length) x $40 \mathrm{~cm}$ (width) x $5.0 \mathrm{~mm}$ (thickness), and consisted of 7 plies. At first, as many as 10 longthin bamboo pieces of $3.0 \mathrm{~cm}$ (width) $\times 1.3 \mathrm{~mm}$ (thickness) was glued together through their edge surface lengthwise surface horizontally to produce bamboo veneer. Each TRF formula was used with glue spread of $0.125 \mathrm{~g} / \mathrm{cm}^{2}$ per glued surface area. 
Afterwards, the resulting bamboo veneer were assembled into ply-bamboo (seven plies vertically) by bonding together so that the direction of each ply ran perpendicular to each other. The same formula of TRF was also used for gluing, with the glue spread of $0.125 \mathrm{~g} / \mathrm{cm}^{2}$ as well. In order to accelerate the curing (hardening) of the TRF adhesive, hotpressing was employed at $20 \mathrm{~kg} / \mathrm{cm}^{2}$ pressure and at $130^{\circ} \mathrm{C}$ for 20 minutes. Then the resulting plybamboo was conditioned for seven days and evaluated by measuring its physical and mechanical properties, glue-bond qualities and formaldehyde emission. The measurement was conducted and referred to the Indonesian (SNI, 1999) and Japanese Standard for structural (JAS, 2003).

\section{HASIL DAN PEMBAHASAN}

\section{A. Adhesive Performance}

Table 1 revealed the characteristics of TRF i.e. crystallinity and melting/glass transition temperature as well as other related aspects (polymer components). It turned out that the TRF crystallinity and melting/glass transition temperature ranged $44.59-81.31 \%$ and 124.65 $277.14^{\circ} \mathrm{C}$ respectively. The TRF copolymer that produces the best adhesives for ply-bamboo assembly was the one with high enough crystallinity and the highest of melting/glass transition temperature. From Table 1, therefore, the TRF adhesive with molecular composition of $1: 0.5: 1$ for tannin, resorcinol, and formaldehyde, respectively was decided as the best one. This TRF afforded $51.33 \%$ of crystallinity and $277.14^{\circ} \mathrm{C}$ of melting/glass transition temperature.

The TRF adhesives with such optimum $T$ : R : F composition $(1: 0.5: 1)$ exerted favorable quality (Table 2) compared to the phenol formaldehyde (PF) adhesive, based on Indonesian standard (SNI, 1998), but it did not perform satisfactorily as the imported phenol resorcinol formaldehyde (PRF) adhesive (Table2).

Figures 1 revealed the diffractogram of TRF adhesive with optimum composition and each individual component ( $\mathrm{T}, \mathrm{R}, \mathrm{F})$ during copolymerization. It strongly showed that the diffractogram characterization of TRF adhesive was between those of individual component. Meanwhile, Figure 2 correspondingly disclosed the thermogram of TRF, each individual component and PRF as well. It reveals that the thermogram characteristics of TRF adhesive during copolymerization ran also between those of its individual component. Further, compared to the thermogram characteristics of PRF adhesive, it turns out that those of TRF adhesive with optimum composition was almost similar in pattern and trend except for the intensity $(\mathrm{V}$ DTA), where the later was slightly lower. This again strengthened the decision to determine the optimum composition of TRF copolymerization at $\mathrm{T}: \mathrm{R}: \mathrm{F}=1: 0.5: 1$ (Table 1$)$.

Table 1. Component and characteristics of TRF polymer adhesive

\begin{tabular}{lcc}
\hline \multicolumn{1}{c}{ Polymer Component } & Crystallinity ${ }^{\mathbf{1}} \mathbf{\%}$ & Melting Transition Temperature $^{2},{ }^{\mathbf{}} \mathbf{C}$ \\
\hline Tannin & 42.89 & 230.47 \\
\hline Resorcinol & 85.98 & 226.86 \\
\hline Paraformaldehyde & 69.18 & 128.59 \\
\hline T:R:F $=1: 0: 1$ & 81.31 & 124.65 \\
\hline T:R:F $=1: 0.2: 1$ & 44.59 & 228.08 \\
\hline T:R:F $=1: 0.5: 1$ & $\mathbf{5 1 . 3 3}$ & $\mathbf{2 7 7 . 1 4}$ \\
\hline T:R:F $=1: 0.7: 1$ & 69.20 & 265.84 \\
\hline T:R:F $=1: 0.9: 1$ & 61.40 & 254.44 \\
\hline T:R:F $=1: 1.1: 1$ & 54.24 & 236.33 \\
\hline PRF & 51.53 & $\mathbf{2 7 3 . 0 4}$ \\
\hline
\end{tabular}

Remarks: $\mathrm{T}=$ tannin, $\mathrm{R}=$ resorcinol, $\mathrm{F}=$ formaldehyde, $\mathrm{PRF}=$ Phenol resorcinol Formaldehyde; ${ }^{1}$ Obtained using XRD instrument; ${ }^{2}$ Obtained using DTA instrument 
Table 2. Characteristics of TRF adhesives compared to others

\begin{tabular}{cccc}
\hline Properties & TRF $^{1}$ & PF $^{2 *}$ & PRF $^{\mathbf{3}}$ \\
\hline Visual & $\mathrm{L}, \mathrm{RB}$ & $\mathrm{L}, \mathrm{RB}$ & $\mathrm{L}, \mathrm{RB}$ \\
Specific gravity & 1.08 & $1,165-1,2$ & 1,15 \\
Solid content $(\%)$ & 46,0 & $40-45$ & 57,03 \\
Viscosity (Poise) & 1.6 & $1,3-3,0$ & 3,4 \\
Acidity (pH) & 10.5 & $10,0-13,0$ & 8,0 \\
\hline
\end{tabular}

Note: L, RB = Liquid shape, red-brown color, ${ }^{1}$ at T:R:F composition of 1:0.5:1 ${ }^{2} \mathrm{SNI}(1998),{ }^{3}$ Aczonobel (2003)

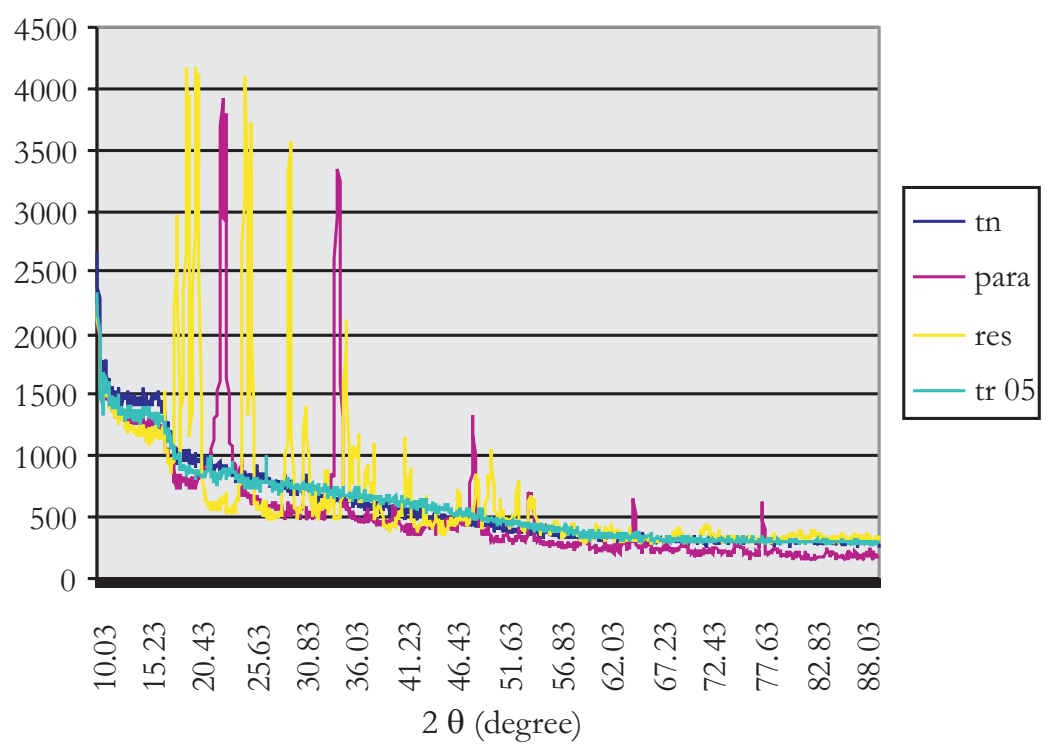

Figure 1 Diffractogram of TRF adhesive and each individual component ( $T$, R, and $F$ )

Remarks: tr05 $=$ tannin-resorcinol-formaldehyde (TRF) adhesive at mole ratio of $\mathrm{T}: \mathrm{R}: \mathrm{F}=1: 0.5: 1 ; \mathrm{tn}=$ tannin; para/pFormaldehyde $=$ paraformaldehyde; form $=$ formaldehyde; res $=$ resorcinol; PRF $=$ phenol-resorcinolformaldehyde.

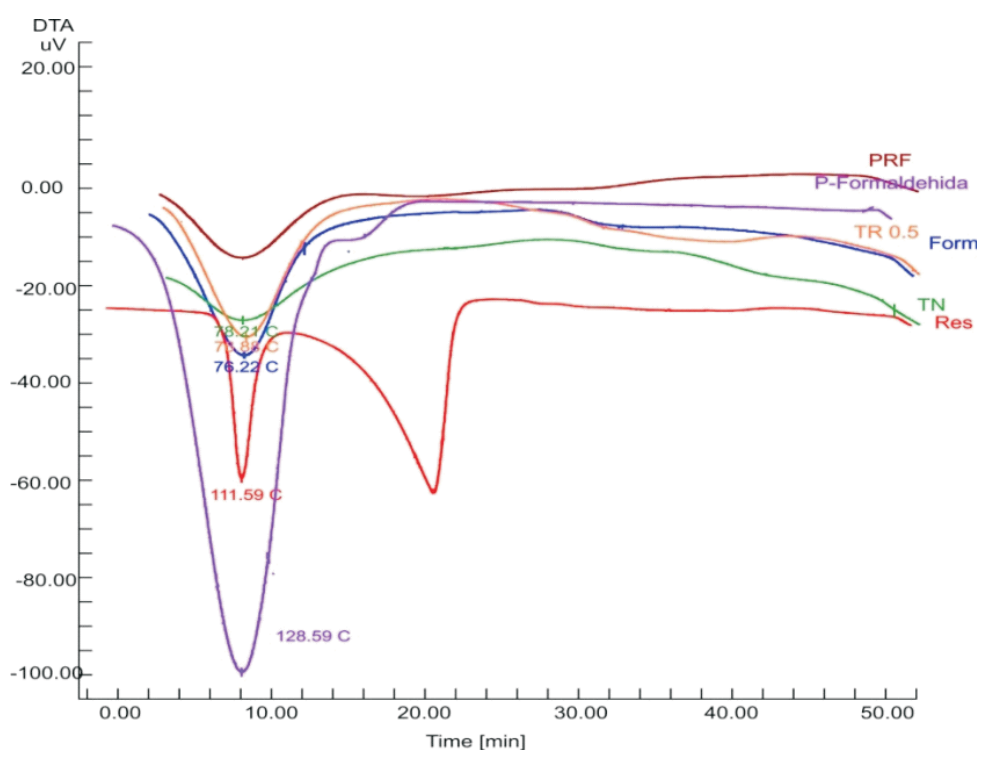

Figure 2. Thermogram of TRF adhesive and each of individual components (T, R, and F)

Remarks: tr05 $=$ tannin-resorcinol-formaldehyde $(\mathrm{TRF})$ adhesive at mole ratio of $\mathrm{T}: \mathrm{R}: \mathrm{F}=1: 0.5: 1 ;$ tn $=$ tannin; para $/ \mathrm{p}$ Formaldehyde $=$ paraformaldehyde form $=$ formaldehyde; $\quad$ res $=$ resorcinol; $\quad$ PRF $=$ phenol-resorcinolformaldehyde. 


\section{B. The Properties of Ply bamboos}

The properties of ply-bamboo made of bamboo veneers bonded together using TRF adhesive are presented in Table 3. It turns out that such properties could fulfill the criteria of Indonesian and Japanese Standards (i.e. SNI and $J A S$ respectively) for structural plywood, except for the MOE. Expectedly this slight MOE drawback can be improved using greater amount of TRF or exerting longer pressing time during ply-bamboo manufacturing. Further, with respect to the formaldehyde emission, it reveals that such emission from the experimented ply-bamboo using TRF adhesive was much lower than those stipulated by the standards (SNI and JAS) for structural plywood (Table 3).

Judging from the scrutiny result on strength properties and formaldehyde emission, it strongly indicates that the experimented ply-bamboo bonded with TRF adhesive could perform as effectively as the structural plywood using any other formaldehyde incorporated adhesives.

Table 3. Characteristics of ply bamboo

\begin{tabular}{lccc}
\hline & & \multicolumn{2}{c}{ Standard } \\
\cline { 3 - 4 } \multicolumn{1}{c}{ Properties } & TRF & SNI & JAS \\
\hline MOR, $\mathrm{kg} / \mathrm{cm}^{2}$ & $1,214.62$ & 140 & 420 \\
$\mathrm{MOE}, \mathrm{kg} / \mathrm{cm}^{2}$ & 19,493 & 85,000 & 85,000 \\
Bonding strength, $\mathrm{kg} / \mathrm{cm}^{2}$ & 38,40 & 7.0 & 7.0 \\
Delaminating, cm & 0 & 2.5 & 2.5 \\
Formaldehyde emission, $\mathrm{mg} / \mathrm{L}$ & 0.043 & $0,5-5,0$ & $0,3-0,5$ \\
\hline
\end{tabular}

\section{CONCLUSION}

The optimum composition for each of the individual component that incorporated tannin $(\mathrm{T})$, resorcinol $(\mathrm{R})$, and formaldehyde $(\mathrm{F})$ in the formulation of TRF copolymer adhesive was decided at the $\mathrm{T}: \mathrm{R}: \mathrm{F}$ 's mole ratio of $1: 0.5: 1$. Such decision was judged from the XRD and DTA scrutinies: that the formulated TRF adhesive exhibited high crystallinity $(51.33 \%)$ and high melting/glass transition temperature (277.14 $\left.{ }^{\circ} \mathrm{C}\right)$.

The ply-bamboo panel with the TRF adhesive at such optimum composition exhibited its physical and strength properties, and emission characteristics i.e. density at $0.904 \mathrm{~g} / \mathrm{cm}^{3}, \mathrm{MOR}$ $1,214,62 \mathrm{~kg} / \mathrm{cm}^{2}$, MOE $19,493 \mathrm{~kg} / \mathrm{cm}^{2}$, internal bonding strength $38.04 \mathrm{~kg} / \mathrm{cm}^{2}$, zero-percent $(0 \%)$ delamination, and formaldehyde emission at $0.043 \mathrm{mg} / \mathrm{l}$. The physical and strength properties and emission characteristics of the ply-bamboo bonded with the renewable TRF adhesive could mostly fulfill the criteria of the Indonesian and Japanese Standards for structural plywood bonded with the conventional, not renewable adhesive (e.g. UF and PF) with the exception of MOE. Such MOE drawback could expectedly be improved by using greater amount of TRF adhesive and/or imposing large pressing duration.

The much lower formaldehyde emission from the TRF adhesive compared to the conventional UF and PF adhesives strongly suggests its potential use in the gluing of wood or other lignocellulosic products which sound environmentally friendly. To ultimately sum up, the TRF adhesive indicatively could afford an effective performance as the conventional UF and $\mathrm{PF}$ adhesives in the reconstituted wood or other lignocellulosic products (e.g. plywood and plybamboo). In this way, the TRF adhesive can expectedly sooner or later replace the conventional PF and UF adhesives derived from non renewable stuffs, thereby indicatively contributing to the mitigation of climate change, and hence easing the global warming.

\section{REFERENCES}

Akzonobel. 2003. Synteko Phenol-Resorcinol Adhesive 1711 with Hardeners 2620, 2622, 2623. Jakarta: Casco Adhesive.

Gardner, D.J and R.L Anido. 2002. Adhesion between Wood and Fiber Reinforced polymers: Bonding Issues. http://www. 
umaine.edu./adhesion/gardner/5502002/ wood-frp $\% 20$ adhesion. Pdf. Accessed at January 8th, 2003.

Pizzi, A. 1993. Advanced Wood Adhesive Technology. Dekker, New York. 48 pp.
NStandard Nasional Indonesia. 1998. Kumpulan SNI Perekat. Badan Standardisasi Nasional. Jakarta.

Standard Nasional Indonesia. 1999. Kayu Lapis Struktural SNI 01-5008.7-1999. Badan Standardisasi Nasional. Jakarta. 